\title{
César Moro: Poeta Híbrido Y Transnacional
}

\author{
César Moro: Hybrid And Transnational Poet
}

\author{
Yolanda Westphalen Rodríguez \\ Universidad Nacional Mayor de San Marcos \\ yolanda.westphalen@gmail.com
}

\begin{abstract}
Resumen
La eufonía, esa sonoridad agradable que resulta de la acertada combinación de los elementos acústicos de las palabras, es un componente decisivo de la poética moreana y clave en la elección del francés como lengua de escritura. Así, el artículo abordará tres aspectos de la problemática del uso de la lengua en la obra de César Moro. En primer lugar, su definición como un escritor bilingüe de expresión francesa; en segundo lugar, su adopción del francés como parte de un transnacionalismo surrealista; y, por último, las características de su hibridismo intercultural francófono que lo llevó a construir su propia diglosia poética y cultural.

Palabras clave: César Moro, surrealismo, diglosia, interlengua, hibridismo intercultural
\end{abstract}

\begin{abstract}
Euphony, that pleasing sonority that results from the correct combination of the acoustic elements of the words, is a decisive component of Moro's poetry and key in the choice of French as his language of writing. Thus, the paper will address three aspects of the problem of the use of language in César Moro's work. First, his definition as a bilingual writer of French-expression; Secondly, its adoption of French as part of a surrealist transnationalism; And, last, the characteristics of his Francophone intercultural hybridism that led him to build his own poetic and cultural diglossia.
\end{abstract}

Keywords: César Moro, surrealism, diglossia, interlanguage, intercultural hybridism

\section{Introducción}

En su ensayo "Las lenguas y la poesía”, Emilio Adolfo Westphalen (1984) hace un paralelo entre José María Arguedas y César Moro que le sirve para reflexionar sobre los problemas literarios de la relación entre las lenguas en el caso de los escritores bilinguies. En él afirma: "La mayor parte de los poemas publicados e 
inéditos de Moro fueron escritos en francés - pero la serie de La tortuga ecuestre lo fue en español y por los mismos años en que escribía Lettre d'amour". Reflexiona el crítico y poeta peruano sobre uno de los aspectos más destacados de la conformación del campo intelectual de las décadas del 30 y del 40 del siglo XX: la postura desarrollada por los principales intelectuales de lo que denominaré el frente antioligárquico ante la problemática linguiística y cultural en las que se expresaban las literaturas peruanas, y la conciencia cada vez mayor de la importancia de la lengua como materia prima del arte verbal y de toda reflexión metaliteraria. Se trataba no solo de hacer uso de una lengua, sino de explorar sus mecanismos de creatividad. Para lograr transmitir una infinitud de mensajes nuevos, se debían crear enunciados que nunca antes habían sido producidos, ampliar el universo semántico del sistema linguístico a partir de alterar y jugar con los elementos composicionales y las estructuras recurrentes ${ }^{1}$. Todas las virtualidades del sistema debían ser exploradas, incluso aquellos caminos considerados cerrados o imposibles desde el punto de vista tradicional de las estructuras de la lengua estándar.

Sin embargo, no solo se trataba de descubrir nuevas potencialidades creativas en su propia lengua materna, sino de rastrear los mecanismos de creatividad en el proceso de apropiación de otros idiomas, revelar los sustratos de la lengua origen y las formas de apropiación de la lengua objetivo; lo interesante no era convertir la una en la otra, sino descubrir el proceso de identidad y diferencia en las relaciones interlinguiísticas, además de descentrar los universos semióticos estables desde los márgenes. Moro lo hizo a partir de dos idiomas considerados centrales en el mundo occidental, el castellano y el francés, y Arguedas empleando la lengua del colonizado y la del colonizador, el quechua y el español. El bilingüismo, el multilingüismo y el translinguiismo fueron, por lo tanto, considerados favorables para las incursiones en nuevos territorios culturales y en la apropiación de los mecanismos multilinguiísticos y multiculturales de creación. En esta oportunidad voy a referirme a uno de los aspectos más destacados de la obra de Moro: el hecho de que haya producido casi la integridad de su creación 
lírica y dramática en francés e incluso, tal como se ha revelado en la correspondencia que le dirigió a Emilio Adolfo Westphalen, casi la mayoría de sus cartas, lo que confirma la elección del francés como su lengua poética y de escritura. El artículo abordará tres aspectos de la problemática del uso de la lengua en la obra de César Moro. En primer lugar, su definición como un escritor bilinguie de expresión francesa; en segundo lugar, su adopción del francés como parte de un transnacionalismo surrealista; y, por último, las características de su hibridismo intercultural francófono que lo llevó a construir su propia diglosia poética y cultural.

\section{Escritor bilinguie y escritura de expresión francesa}

En su libro Poétique francophones, Dominique Combe señala lo siguiente: "La langue 'd'écriture', seule, définit le texte francophone comme texte littéraire" (1995, p. 25). Este requisito mínimo es, sin embargo, también complejo. Queda así por definir desde cuándo se elige el francés, por qué se lo adopta como lengua de escritura y qué tipo de francés se habla. Hay que considerar, igualmente, la distinción entre los géneros del discurso ordinario y los géneros literarios propiamente dichos, porque estos últimos varían de acuerdo con cada cultura. Se requiere que el texto, y no solo el metatexto o el paratexto se escriba en francés y que haya una continuidad en el uso de esta lengua. En cierta medida, supone un proyecto de escritura realizado esencialmente en francés, aunque este puede combinarse con el uso de otra u otras lenguas, como sucedió con el castellano en el caso de Moro.

La elección del francés como lengua de escritura tuvo en Moro características específicas. Fue un aprendizaje tardío, dado que recién lo adquirió como segunda lengua a partir de su viaje y permanencia en Francia de 1925 a 1933, es decir, entre los 22 y 30 años de edad. En este periodo eligió una poética, el surrealismo, y una lengua, el francés, como medio de expresión artística. Se trató, en suma, de un renacimiento y de la construcción consciente y deliberada de una nueva identidad, proceso que el artista ya había iniciado en Lima en 1923 cuando decidió cambiar su nombre de Alfredo Quíspez Asín Mas a 
César Moro. En una carta dirigida a su hermano Carlos explica el porqué de tal decisión:

La cuestión esa del nombre ha sido siempre para mí una tortura y naturalmente he tratado de sacudírmela. Cuando llegó tu carta hace cuatro o cinco días, ya tenía - después de mucho pensar y no encontrar- ya tenía un nombre: CÉSAR MORO [...]. No sé qué te parecerá el nombre; a mí me suena bien, es eufónico. Conste que no es de mi invención, y esto me friega, lo encontré en un libro de Gómez de la Serna. Felizmente no es un personaje importante ni interesante. [...] Por supuesto cuando me escribas pondrás en el sobre: Sr. Don César Moro. (En Coyné, 2015, p. 65)

La eufonía, esa sonoridad agradable que resulta de la acertada combinación de los elementos acústicos de las palabras, es un componente decisivo de la poética moreana y clave en la elección del francés como lengua de escritura. Se puede señalar que la suya es una escritura ligada a una oralidad, distinta a la del castellano pero oralidad al fin y al cabo. La importancia de la sonoridad a nivel poético apunta a una poesía para ser leída en voz alta, porque la materialidad del significante es parte de su sentido. En el caso de la correspondencia, la escritura se enfoca en reproducir y simular la oralidad del coloquio, el flujo conversacional, por eso no importan las grafías ni la corrección ortográfica (las consonantes dobles escritas con solo una consonante o la escritura “tu est"), sino la pronunciación. Mientras la pronunciación no varíe, como en los dos ejemplos antes mencionados, la oralidad de la conversación y su función comunicativa se garantizan.

A diferencia del castellano estándar que tiene 5 vocales y 19 consonantes, el francés estándar posee de 20 a 21 consonantes y de 11 a 16 vocales, según la forma de contar. La elección del francés por Moro pudo tener que ver, por ende, con las posibilidades fónicas y eufónicas que la lengua le brindaba y que correspondían con su búsqueda y propuesta poética surrealista. La riqueza del sistema vocálico y consonántico del francés parece haberse convertido en elemento clave para la obra poética de Moro ${ }^{3}$. Lo que producen estos efectos fónicos en el lector es una impresión material hecha en y a través de los sentidos. El poeta busca que el lector siga un método de conocimiento 
alternativo que va de la sensación a la percepción y de ahí a una aprehensión vivencial de la realidad. El significante debe permitir la asociación y la evocación más allá de los límites de un sistema linguiístico. La asunción de un nuevo idioma de expresión va de la mano, entonces, de la elección de una nueva poética que corresponda con su nueva identidad, en la que la poesía y el arte son vistos como una nueva forma de vida.

La apropiación del francés como lengua de escritura y la capacidad de jugar con el significante de dicha lengua (por ejemplo, el juego con las palabras l'amer [lo amargo], y la mer [la mar] transmite la imagen de lo salobre y amargo del mar) es más notable en Moro dado que solo tuvo ocho años de inmersión linguiística. En ellos utilizó indistintamente el francés como lengua coloquial y lengua de escritura; Moro nunca regresó a Francia, pero escribió casi todos sus poemas, su prosa poética, su pieza de teatro y hasta parte de su correspondencia en francés. Su bilingüismo era en realidad una diglosia porque si bien escribía en francés, mientras estuvo en el Perú y México tenía que expresarse en castellano. Dado que el francés no era una lengua nacional ni administrativa en estos países, la comunicación pública —oral y escrita—, la tuvo que hacer en español. Así, las conferencias que dio en Lima o México, los ensayos publicados en revistas peruanas como El Uso de la Palabra y Las Moradas o mexicanas como El Hijo Pródigo, los manifiestos como el que escribió para la Exposición Internacional Surrealista en 1940 en México, todos los publicó en castellano. Reservó el francés para su obra artística y literaria, para algunos panfletos como El obispo embotellado, y para la comunicación oral y escrita con los amigos y allegados surrealistas. Su poesía, los textos insertados en collages o pinturas, las cartas a Westphalen y su comunicación con el grupo surrealista en México la realizó sobre todo en francés.

Las razones que tuvo en mente para tomar tal decisión probablemente no se sepan nunca. Lo que sí puede hacerse es estudiar las implicancias de tal decisión en el contexto histórico, social y cultural de su época, así como en las condiciones individuales de su propia vida. Se puede deducir, en tal sentido, el 
contenido simbólico de ese gesto y frente a qué propuestas y fuerzas el bilingüismo se erigió ante él como una opción.

\section{Moro y el transnacionalismo surrealista}

La elección del francés no tiene para Moro los visos neocolonialistas e imperialistas que tuvo y tiene para los escritores de las antiguas colonias francesas. La lengua colonial en el Perú fue el castellano, que se encontró en una situación de diglosia respecto de las lenguas nativas ancestrales. El debate planteado a inicios del siglo XX sobre el objeto de estudio de la literatura peruana, el corpus y la lengua en la que esta se expresa puso en primer plano las opciones contradictorias y visiones ideológicas contrapuestas de los diversos actores del campo literario. Un sector importante de los estudiosos de la literatura ligado al poder oligárquico (José de la Riva-Agüiero, Ventura García Calderón) postuló una postura de corte criolla hispanista. Los indigenistas, por su parte, planteaban una literatura en castellano, pero que incorporara el legado indígena porque, según ellos, la presencia de la tradición histórica y el folclore son elementos indispensables para lograr una simbiosis de lo quechua con lo criollo y producir así una literatura auténticamente nacional. José Carlos Mariátegui anunció la posibilidad de una literatura indígena, pero advierte que esta aún no existe. Las dos posturas en disputa en el campo literario de la época eran, entonces, entre los criollos hispanistas y los indigenistas, el francés no era ni lengua nacional ni del colonizador, solo era hablado por sectores de la intelligentsia y de la élite cultural, o por los diplomáticos.

La decisión de Moro subvierte los términos del debate sobre la lengua y su papel en la formación del campo intelectual y literario peruano. El debate mostraba la aceptación, implícita o explícita, por parte del sector dominante del campo intelectual, tanto de la existencia de una situación de diglosia en el Perú en la que el español se ha impuesto como la lengua dominante respecto del quechua, el aimara y las lenguas amazónicas, como de la justificación ideológica del colonizador y sus argumentos sobre la supuesta universalidad, racionalidad y superioridad intelectual del castellano debido a su capacidad de abstracción y 
categorización, así como por su papel de lengua general y articulador de la tradición histórica ${ }^{4}$. La posición, incluso de los intelectuales más avanzados como José María Arguedas, no discutía la necesidad de una narrativa contemporánea en lenguas nativas, sino modificar el castellano al incorporar el léxico, la sintaxis y la visión del mundo andino en sus relatos. Arguedas conservó el quechua para la poesía y la recopilación y transcripción de huainos, leyendas y cuentos ancestrales, a los que consideraba géneros propios dentro del universo andino. Su propuesta de escribir obras de dichos géneros en quechua, incluso en formato bilinguie, implicaba no solo convertir al hablante de lenguas nativas en sujeto de la escritura, sino crear un nuevo público lector.

Si el castellano mantenía su posición dominante en la situación de diglosia, ello se debía al prestigio de la lengua escrita, lo que la convertía en el mundo intelectual peruano en portadora de la tradición científica y literaria respecto de las demás lenguas del Perú. Moro creó su propia diglosia, convirtió al castellano en la lengua oral y subordinada al francés; simbólicamente lo que hizo fue colocar al castellano en la situación de inferioridad en que este ponía a las lenguas nativas. El francés se convirtió, para él, en la lengua de escritura y de prestigio y el castellano en la lengua cotidiana y de oralidad. Pero Moro no eligió el francés en función de los clásicos estereotipos asociados a dicha lengua: su supuesto carácter racional y universal, argumentos etnocentristas utilizados por la Francia colonizadora e interiorizada o introyectada por los colonizados del área de influencia francófona. Moro adoptó el francés como una especie de lengua franca del surrealismo y para él representó el medio para expresar su oposición a las posturas de ambos sectores en pugna del campo literario peruano.

La opción por la lengua franca del surrealismo representaba, más bien, la oposición a la racionalidad occidental y la apuesta por la liberación del lenguaje de todo sentido para convertirlo, a través de la poesía y la escritura automática, en un medio de acceso a una realidad otra, emocional, de imaginación y sensibilidad. El francés para Moro era la lengua vehicular de un 
identidad del sujeto de enunciación.

\section{Diglosia}

El concepto de interlengua ha sido desarrollado en el campo de la didáctica de las lenguas y se apoya en los estudios de la linguística cognitiva (Alexopoulou 2010). Se entiende por ella la lengua que se forma en el practicante de una lengua extranjera cuando se este ve confrontado con el aprendizaje de los elementos de dicha lengua. La versión de la lengua objetivo que el estudiante posee no coincide plenamente con la de la lengua en proceso de adquisición.

Lo novedoso de esta aproximación al estudio del aprendizaje de las lenguas es la postura adoptada frente a los "errores" cometidos por los estudiantes de lengua extranjera. Desde esta visión, los practicantes de una lengua extranjera están dotados para usar habilidades cognitivas de manera creativa; es decir, elaboran hipótesis sobre la estructura de la lengua objetivo, construyen modelos que ponen a prueba y los modifican si no resultan adecuados. En cada etapa del aprendizaje se desarrolla un sistema transitorio del lenguaje que no es equivalente ni a la primera ni a la segunda lengua: se constituye así una interlengua.

Aplicada a la obra de Moro y su uso del francés, este concepto se revela como sumamente pertinente. Obviamente, su dominio del francés debe de haber pasado por diversas etapas, pero es importante hacer consciente este territorio liminar de hibridez linguiística como parte de su escritura. Si bien es notoria una mayor presencia de "errores" o interferencias en la correspondencia dirigida a Westphalen que en su poesía, lo que puede explicarse por la distinta funcionalidad y condiciones de escritura de ambas — revisión en el caso de la primera; inmediatez, espontaneidad, premura o falta de máquina con teclado francés en el caso de la segunda-, es importante ver que en todos los casos hace uso de un nivel de interlengua que lo caracteriza.

En el caso específico de la poesía de Moro, Gaelle Hourdin (2016), una de las recientes estudiosas de su obra, argumenta que la peculiaridad del bilingüismo de Moro se encuentra en la copresencia e interpenetración del 
campo literario internacional e implicaba la adhesión a una nueva declaración de los derechos del hombre.

\section{Hibridismo intercultural francófono}

Además, como no existe el bilingüismo perfecto y es casi imposible un dominio idéntico de ambas lenguas tanto en el ámbito oral como en el escrito; como el dominio del francés varía si se lo ha aprendido como lengua primera o segunda y dependiendo de los diferentes grados de francofonía misma, el francés de Moro es también un francés marcado por el bilingüismo y la diglosia. Moro no asume la variedad parisina estándar del francés ni su propuesta clasicista; la variante que él adopta descentra al francés al revelar en él un sustrato del castellano, fenómeno esencial en la construcción del estilo y la poética del autor. Se trata de un nivel de interlengua, de apropiación del francés que emula la apropiación que los quechuahablantes hacen del castellano; es decir, una lengua en constante proceso de apropiación, con distintos grados de interferencia marcada por numerosos particularismos provenientes del castellano que revela una nueva identidad. Una lengua liminal marca de su idiolecto.

Tal como lo plantea el poeta quebequés Fernand Ouellette, cuando uno habla su versión diglósica de francés, en su caso el "franglais", "se convierte para los demás en un bárbaro" ${ }^{5}$. Como él, Moro habla una lengua híbrida, una suerte de "frañol”; maneja un amplio léxico, propio del francés estándar; pero en el plano sintáctico y ortográfico lo combina con un nivel de interlengua entre el francés y el español. No se siente, sin embargo, un extranjero, porque la lengua objetivo es asumida como lengua vehicular de un movimiento internacional como el surrealismo. El francés es transformado por la explosión de la lengua hecha por los franceses mismos y por la internacionalización de los surrealistas; es vista como una lengua surrealista internacional que incorpora toda la riqueza de las lenguas y variedades surrealistas particulares. Al hacer uso de esta especie de frañol, Moro reivindica el lugar de enunciación de su adhesión al surrealismo “desde el Perú, por el surrealismo mundial”. La apropiación de la lengua franca con sus variantes idiolectales es parte de esta reivindicación del lugar y de la 
francés y el español. Moro juega con las homofonías entre el francés y el castellano. Tal es el caso del título, muy conocido por cierto, de uno de sus poemarios Amour à mort, que oralmente remite a la equivalencia de la palabra amor en francés y en castellano, pero rompiendo con la escritura morfosintáctica escrita del término en español. Hace lo mismo con la palabra sol en ambos idiomas ("Le sol plus cher que le soleil"). En dicho verso se forma un quiasma, pero además del parecido entre las dos palabras en francés "sol" (suelo) y "soleil" (sol), para el lector hispanohablante se añade una equivalencia semántica más, sol es la traducción de "soleil" (Hourdin, 2016, p. 34). En la poética de Moro, entonces, el bilingüismo y el interlingüismo constituyen un factor fundamental.

Algunos ejemplos de la presencia de un sustrato castellano se evidencian también en sus cartas. La presencia de "errores" recurrentes en el conjunto de la correspondencia — como el uso de una sola consonante donde el francés usa consonantes dobles - nos habla de un francés subvertido por la presencia de un sustrato castellano: lengua híbrida y mestiza, que es también una de las formas de reproducir y emular la apropiación que hace el quechua de la cultura y la lengua occidental para descentrarla desde una perspectiva andina. Moro repite el procedimiento colocándose así consciente y deliberadamente en una posición de automarginación frente a la tradición criolla hispanista a la que busca descentrar. Dado que él no habla el quechua, subordina el castellano a la lengua franca del surrealismo, al mismo tiempo que descentra el francés desde una perspectiva latinoamericana y/o peruana.

En Moro existe un cierto rasgo de esquizofrenia cultural inherente a la decisión de convertirse en un escritor de expresión francesa. Solo puede hacer ello a condición de un estricto reparto de tareas, de una jerarquización, en suma, de una diglosia entre las lenguas y las visiones del mundo que implican: el castellano para la vida cotidiana, el francés para la escritura poética. Lejos de lograr una síntesis armoniosa, el recurso a ambas lenguas implica un desgarramiento y desposeimiento del sujeto que lleva incluso a un estallido, que se hace patente en la correspondencia. Es así porque las cartas a Emilio Adolfo 
Westphalen son también un territorio del entre-dos, fragmentos de escritura ordinaria y prosaica de información junto a segmentos poéticos y críticos. En ellas, a veces, cambia de una lengua a otra para poder expresar lo que siente. Así, en la carta del 26 de mayo de 1944, Moro inicia en francés y en medio de un comentario crítico contra Xavier Abril vira al castellano.

Moro es consciente de la importancia del código linguiístico como portador de una ideología y visión del mundo. Sabe que los criollos hispanistas propugnan un clasicismo y purismo en la lengua y la literatura; por eso recurre al uso deliberado de un castellano con "faltas ortográficas" y expresiones coloquiales de la variedad dialectal de México. Por ejemplo, en la carta del 1 de octubre de 1946, escrito que también inicia en francés para luego terminarlo en castellano, escribe de la siguiente manera:

Debes haber recivido ya carta mía, la puse al correo hace unos días después de aberla tenido guardada. Convensido de que la avia enbiado ya.

El viernes estuve en el chingado consulado del Perù. Pinche país, el Cónsul había recibido un papel diciendo que comprara un pasaje por vía marítima y de tercera clase para mí. No te puedes imaginar lo desagradavle que sentí ante la insolencia de ese insulto semioficial y semicómico.

En la continuación de la mencionada carta, hecha el 2 de octubre, Moro juega con los códigos y modifica el castellano recurriendo a usos arcaicos empleados en el Quijote, tales como "leelle”, “escrevir”, envialla”. Es su manera de reivindicar su postura antihispanista y llevar a la práctica lo que planteó en uno de sus artículos más conocido: “Todos sabemos o deberíamos saber que el español es una lengua estancada desde el Siglo de Oro" (Moro, 1958, p. 18). Actualiza arcaísmos y modifica el castellano, ya sea haciendo uso de las dobles consonantes — de las que se olvida en francés — o combina francés y castellano cuando le dice al amigo: "Ahora estoy haciendo una nature demi-morte, con una col, un florero y dos calabacitas y un elote (choclo)".

El efecto de extrañamiento linguiístico lo ubica en el terreno del entre- 
dos, el desenraizamiento y la desterritorialización; hace así consciente el proceso de toda creación literaria, el conflicto entre el lenguaje como materia prima y medio de la literatura y la liberación del lenguaje de todas sus ataduras propuestas por el surrealismo. Sin embargo, para Moro, el surrealismo no es una simple escuela literaria, es una forma de conocer el mundo y una forma de vida. El extrañamiento de una lengua segunda no es solo un recurso poético, es parte de una concepción del mundo que comparte con Westphalen y de la que este también fue consciente.

Durante su estadía en México, el francés fue el medio de comunicación entre los miembros del grupo de exiliados surrealistas. Al escribir Moro a Westphalen en francés, está incluyendo al amigo en este circuito surrealista, lo está haciendo partícipe de este proceso de apropiación de un idiolecto, de un estilo propio de vida y de escritura. A su retorno a Lima y cuando Westphalen viajó a Estados Unidos, Moro ya no le escribe al amigo en francés sino en castellano. El cambio de código en la correspondencia puede explicarse por el alejamiento del propio Moro del círculo de expatriados surrealistas, lo que no sucede con su poesía, porque la adhesión a la poética del surrealismo persiste. El francés deja de ser la lengua de comunicación cuando su cotidianidad ya no es la de un miembro más del grupo surrealista y se convierte, más bien, en lengua de trabajo porque se gana la vida como profesor de dicha lengua en el Colegio Militar Leoncio Prado.

Cuando Moro escribe al amigo en francés está también subvirtiendo la supuesta división entre los denominados géneros ordinarios y los literarios. Está usando la lengua poética para comunicarse, porque sus cartas son también el espacio del entre-dos, el espacio liminal de la amistad entre poetas y amigos que une lo prosaico y lo poético. La correspondencia es una muestra de la esquizofrenia cultural que implica el cambio de código y, con él, de visión del mundo, así como el intento desesperado de vivir simultáneamente los dos polos de una personalidad: su existencia prosaica y cotidiana como un escritor peruano y latinoamericano, a la par que su adhesión al surrealismo y al francés asumido 
como lengua poética y de escritura surrealista. La mezcla linguiística es expresión simbólica de este proceso de yuxtaposición creativa.

\author{
Notas \\ JJuan Carlos Moreno Cabrera (2003) aborda la problemática de las características del \\ lenguaje en su libro Semántica y gramática. También se pueden revisar algunos de esos \\ conceptos en la siguie nte página we b: \\ https://www.academia.edu/7300273/_QU\%C3\%89_ES_EL_LENGUAJE. \\ "'Solo la 'lengua de escritura' define al texto francófono como texto literario" (traducción \\ de YW). \\ ${ }^{3}$ Desde el punto de vista de la retórica, el grupo de Lieja plantea que "[...] el metaplasmo es \\ una operación que altera la continuidad fónica o gráfica del mensaje, es decir la forma de \\ expresión en tanto que manifestación fónica o gráfica" (Grupo Mi, 1987, p. 97). En la \\ poesía de Moro se encuentran fundamentalmente aliteraciones y asonancias que repiten \\ una o varias consonantes o una o varias vocales, respectivamente, al interior del texto. \\ Véase Westphalen Rodríguez (2001). \\ ${ }^{4}$ Respecto de la relación entre las lenguas en el Perú y el fenómeno de la diglosia, se puede \\ revisar: Pérez Silva (2004); también el artículo de Goddenzzi "El recurso linguístico del \\ poder: coartadas ideológicas del castellano y el quechua" (2005), además de Baker (1993) \\ y Garatea (2010). \\ ${ }^{5}$ Dominique Combe cita el comentario en su libro Poétiques francophones (1995, p. 48).
}

\title{
Referencias bibliográficas
}

Alexopoulou. A. (2010). La función de la interlengua en el aprendizaje de lenguas extranjeras. Revista Nebrija de Lingüística Aplicada a la Enseñanza de las Lenguas. Recuperado de http://bit.ly/2qsofbS.

Baker, C. (1993). Las lenguas en la sociedad. En Fundamentos de educación bilingüe y bilingüismo (pp. 67-84). Madrid, España: Cátedra.

Coiné, A. (2015). Cronología. En C. Moro, Obra poética completa (pp. 689-751). Edición crítica André Coyné, Daniel Lefort, Julio Ortega. Poitiers, Francia; Córdoba, España: CRLA, Alción Editora. Colección Archivos.

Combe, D. (1995). Poétiques francophones. París, Francia: Editorial Hachette.

Garatea, C. (2010). Español de América: no una sino varias normas. En Tras una lengua de papel: el español en el Perú (pp. 21-60). Lima, Perú: Fondo Editorial de la PUCP.

García Calderón, V. (1938). El apogeo de la literatura colonial. París, Francia: Descleé 
de Brouwer, Biblioteca de Cultura Peruana.

Godenzzi, J. C. (2005). En las redes del lenguaje: cognición, discurso y sociedad en los Andes. Lima, Perú: Universidad del Pacífico.

Grupo Mi. (1987). Retórica general. Barcelona, España: Paidós.

Hourdin, G. (2016). L'étincelle et la plume : une poétique de l'entre-deux dans l'œuvre de César Moro. Toulouse, Francia: Presses Universitaires du Midi.

Mariátegui, J. C. (1928). Siete ensayos de interpretación de la realidad peruana. Lima, Perú: Minerva Biblioteca Amauta.

Moreno Cabrera, J. C. (2003). Semántica y gramática: sucesos, papeles semánticos y relaciones sintácticas. Boadilla del Monte, España: Machado.

Moro, C. (1958). Los anteojos de azufre. Lima, Perú: Editorial San Marcos.

Pérez Silva, J. I. (2004). Los castellanos del Perú. Lima, Perú: ProEduca-GTZ.

Riva-Agüiero, J. de la. (1905). Carácter de la literatura del Perú independiente. (Tesis de bachillerato). Universidad Nacional Mayor de San Marcos. Facultad de Letras, Lima, Perú.

Westphalen, E. A. (1984). Las lenguas y la poesía. Debate, (28). Lima, septiembre. [Reproducido en Escritos varios sobre arte y poesía. Lima: Fondo de Cultura Económica, 1997, pp. 157-163.]

Westphalen Rodríguez, Y. (2001). La poética del ritual y la escritura mítica de la modernidad. Lima: Fondo editorial de la UNMSM. 